\title{
Vulnerabilidade socioambiental em comunidade ribeirinha: a experiência da Ilha de Deus, Recife/PE
}

Este estudo busca analisar a situação de vulnerabilidade socioambiental observada nos moradores da llha de Deus, comunidade ribeirinha em área periférica da cidade do Recife. Verificou-se quais fatores podem contribuir para a sua mitigação, a partir do papel desempenhado pelas ações e programas do Estado de Pernambuco desde 2009 até os dias atuais, tornando a existência humana mais digna. Foi realizada abordagem de problemas que acarretam a precariedade das condições de vida, como habitação, infraestrutura e serviços sociais pouco eficientes. A partir de estudos comparativos, observou-se que as intervenções realizadas pelo Poder Público com a implantação de projeto de urbanização, participativo e integrado nas dimensões sócio-econômico-ambientais, foi relevante para diminuir a situação de pobreza da população. Foi explanado referencial teórico, abordando a evolução da temática urbana ambiental, a vulnerabilidade socioambiental, o direito à cidade e as políticas públicas. A metodologia utilizada foi comparativa e observacional, tendo sido realizadas pesquisas descritiva e exploratória, com aplicação de questionário e visitas à comunidade. A partir da análise do grau de vulnerabilidade de outros estudos, revelou-se uma melhoria da qualidade de vida mas também incidência de fragilidades, principalmente devido à descontinuidade das obras, bem como falta de ações governamentais integradas que objetivem o fomento à geração de renda.

Palavras-chave: Vulnerabilidade socioambiental; Periferia; Políticas Públicas.

\section{Socio-environmental vulnerability in a riverside community: the experience of Ilha de Deus, Recife/PE}

\begin{abstract}
This research analyzes the socioenvironmental vulnerability found in the residents of Ilha de Deus, a riverside community in a peripheral area of Recife. It breaksdown which factors may contribute to their mitigation, based on the role played by public actions and programs devised by the state of Pernambuco from 2009 until present days, in hopes of improving quality of life in the community. The research approached the problems of precarious living conditions such as housing, infrastructure and civil services. From comparative studies, the interventions made by the Government, through the implementation of an integrated socio-economic-environmental program in a urbanization project, were relevant to reduce the poverty situation of the population. A theoretical framework was explained, on the evolution of the urban environmental theme, the social and environmental vulnerability, the right to the city and public policies. The methodology used was observational and comparative, based on descriptive and exploratory research, with the application of a questionnaire and community visits. Analyzing the degree of vulnerabilityof other studies, revealing an improvement in living conditions, but also the incidence of weaknesses, mainly due to the discontinuity of the works, as well as the lack of integrated government actions aimed at promoting income generation.
\end{abstract}

Keywords: Socio-environmental vulnerability; Periphery; Public Policy.

Topic: Desenvolvimento, Sustentabilidade e Meio Ambiente

Reviewed anonymously in the process of blind peer.
Received: 01/01/2021

Approved: 28/01/2021
Manuella Batista Cavalcanti (iD

Instituto de Tecnologia de Pernambuco, Brasil

http://lattes.cnpq.br/4291069103993327

http://orcid.org/0000-0001-7193-0836

manuella cavalcanti@hotmail.com

Daniele de Castro Pessoa de Melo (D)

Instituto de Tecnologia de Pernambuco, Brasil

http://lattes.cnpq.br/4010783198064867

http://orcid.org/0000-0003-4058-092X

daniele.castro@itep.br
Referencing this:

CAVALCANTI, M. B.; MELO, D. C. P.. Vulnerabilidade socioambiental em comunidade ribeirinha: a experiência da llha de Deus, Recife/PE. Revista Ibero Americana de Ciências Ambientais, v.12, n.1, p.595614, 2021. DOI: http://doi.org/10.6008/CBPC21796858.2021.001.0048 


\section{INTRODUÇÃO}

O aumento demográfico urbano, vivenciado desde o século passado, vem ocasionando consequências negativas na estruturação e ordem das principais cidades brasileiras, desequilibrando o sistema socioambiental, seja nas áreas centrais de preservação, ou nas periféricas, onde os riscos ambientais são maiores diante da instabilidade econômica da população pobre (MAIOR et al., 2014).

A desigualdade na distribuição de renda e oportunidades de acesso aos serviços públicos reflete na qualidade de vida diferenciada entre as pessoas, onde a pobreza e a degradação ambiental se retroalimentam (BARBOSA et al., 2015).

A falta de uma atuação eficaz do poder público, especialmente para o contingente carente, impulsiona ao longo do tempo, o seu deslocamento para áreas periféricas da cidade, normalmente ambientalmente desfavoráveis e sem infraestrutura, produzindo um espaço urbano desigual e excludente, diante da situação de vulnerabilidade socioambiental ali existente (DESCHAMPS, 2004).

A ocupação dessas regiões por favelas ocorre em locais sem interesse pelo mercado imobiliário formal ou com restrição de uso, como encostas de morro, beira de córregos, áreas de proteção ambiental, terrenos sujeitos a enchentes, os quais são mais frágeis do ponto de vista ambiental e frequentemente possuem algum tipo de risco (SILVA et al., 2008).

A relação entre os assentamentos urbanos e a terra, seu suporte físico, sempre provocou alterações positivas ou negativas no meio ambiente. As modificações dos modelos de produção e das relações populacionais influenciam diretamente na natureza desses impactos e, consequentemente, nas condições socioambientais das aglomerações urbanas (SILVA et al., 2008).

Esta análise objetiva o estudo da vulnerabilidade socioambiental na comunidade ribeirinha llha de Deus, que é caracterizada como região periférica da cidade do Recife e apresenta fragilidades no eixo social, econômico e ambiental, a fim de avaliar se houve melhora da situação de risco enfrentada pelos seus moradores.

Busca-se perquirir quais os fatores que colaboram para a vulnerabilidade socioambiental da localidade apesar das políticas públicas já realizadas, a partir da caracterização de suas especificidades sócio territoriais, aferição de suas diferentes dimensões da vulnerabilidade socioambiental e observação das intervenções estatais implementadas no período de 2009 a 2015.

Tal questionamento se faz mister, uma vez que a experiência vivenciada por essa população pode ser utilizada como paradigma para uma gestão urbana-ambiental eficiente e eficaz, visando a implementação de ações estatais em comunidades similares, melhorando a qualidade de vida dos indivíduos.

\section{REVISÃO TEÓRICA}

\section{Vulnerabilidade socioambiental}

A vulnerabilidade socioambiental incorpora as dimensões social e ambiental da vulnerabilidade onde contingentes populacionais em situação de alta fragilidade social se relacionam em espaços suscetíveis a 
eventos naturais diversos e não possuem recursos para responderem adequadamente a uma condição adversa perigosa. Há uma estreita relação entre a localização espacial dos grupos que apresentam desvantagens sociais e aquelas áreas onde há possibilidade de ocorrer algum evento potencialmente danoso, ou seja, populações socialmente vulneráveis se localizam em áreas de risco ambiental (DESCHAMPS, 2004).

A vulnerabilidade socioambiental deve ser estudada em sua interdisciplinaridade, uma vez que ela está conectada ao contexto de adensamento populacional, segregação espacial urbana, processos de exclusão ambiental e injustiças sociais, os quais estão vinculados ao aumento demográfico e à falta de políticas públicas eficazes (MAIOR et al., 2014).

Os graus de vulnerabilidade estão ligados a condições precárias de habitação, nutrição inadequada, serviços sociais pouco eficientes, falta de redes de reciprocidade e contatos, os quais conduzem a uma má resposta aos eventos potencialmente danosos (OJIMA, 2012).

Observa-se, portanto, uma conexão entre o ambiental e o social na análise da vulnerabilidade socioambiental na cidade. Na dinâmica urbana de países em desenvolvimento, onde há carência de controle e planejamento por parte do Estado, bem como falta de cumprimento da legislação urbana, populações segregadas, sem condição socioeconômica de resposta às ameaças naturais, são levadas a viverem em locais ambientalmente inapropriados, os quais têm péssima ou nenhuma infraestrutura ou condição urbanística.

Assim, os pobres e miseráveis passam a viver em áreas de preservação e ou risco ambiental, sem abastecimento de água tratada, coleta de lixo, saneamento, em terrenos com alta declividade, ou junto a cursos de água, manguezais, lixões, geralmente em áreas públicas ou de preservação (MAIOR et al., 2014). Em um contexto ambiental, a falta de infraestrutura urbana pode trazer sérios danos em termos de saúde e qualidade de vida.

Para Hogan (2007, citado por SILVA et al., 2008), existe uma coincidência entre as áreas suscetíveis a eventos naturais danosos e as localidades das cidades que apresentam os piores indicadores sociais, econômicos, acesso a serviços e infraestrutura urbana. Ele identifica, além das disponibilidades materiais, carências ou vantagens diferenciadas que possam dar um maior poder de resposta frente a uma situação de vulnerabilidade, como rede de contatos, acesso à informação, bem como o trabalho como ativo principal e o valor a ele agregado.

Deve-se buscar uma visão holística da questão, partindo de uma compreensão profunda dos problemas atinentes ao meio ambiente urbano com o potencial de impactar na formulação de ações do poder público, orientadas à construção de cidades social e ambientalmente sustentáveis (JACOBI, 2000). Cumpre esclarecer, entretanto, que o modelo de expansão periférica no Brasil prevalece, desde a década de 1950, em um contexto de ausência sistemática do Estado para consecução de políticas públicas integradas e ações articuladas na gestão urbana.

\section{O direito à cidade e as políticas públicas}

Os direitos de cidadania, como viver em uma moradia digna, se relacionam com outros direitos nem sempre confluentes, como os de viver em um ambiente não poluído (SPINK, 2014). 
O direito à cidade, tradicionalmente, tem como ideia de que todo homem precisa de condições básicas para se reproduzir enquanto homem, como o acesso à moradia, educação, saúde, lazer, bem como a preservação do espaço histórico e cultural (SANTOS, 2005). Tais direitos, estão, inclusive expressos na Constituição Federal de 1988, no artigo 5ㅇ, que reconhece o direito das pessoas que vivem na cidade como direito fundamental (BRASIL, 1988).

Conforme lições de Harvey (2012), entretanto, o direito à cidade não se circunscreve apenas à liberdade individual de acesso a recursos urbanos, sendo o direito de mudar a nós mesmos pelas mudanças da cidade. Ele é, na verdade, um direito social, comum, uma vez que essa transformação depende do exercício do poder coletivo de moldar o processo de urbanização. É, ainda, conforme o autor, um processo de construir e reconstruir a cidade e a nós mesmos.

A construção do espaço urbano é o reflexo dos vários interesses conjugados dos atores que interagem com a cidade. O Estado, os agentes imobiliários, proprietários dos meios de produção, proprietários fundiários e grupos segregados são os seus principais agentes (CORRÊA, 1989). Cada um deles atua na cidade a partir da reprodução de seus interesses.

A expansão do processo urbano traz grandes transformações no estilo de vida, sendo que a qualidade da vida urbana se tornou uma mercadoria em um mundo que o consumismo, o turismo e a indústria do conhecimento e da cultura se converteram em importantes itens da economia política urbana (HARVEY, 2012). Tal processo acarreta, em muitas localidades, um esvaziamento de qualquer direito à cidade para as massas, ficando este, em muitos casos, restrito a uma diminuta elite política e econômica, que molda a urbe cada vez mais aos seus interesses. Nesse sentido, afirma Acselrad (2015) que, normalmente, grupos sociais mais despossuídos e vulneráveis sofrem com a desigualdade ambiental resultante da espacialidade do capitalismo liberalizado.

Faz-se urgente a democratização do direito à cidade em seu sentido mais amplo a fim de mitigar as diferenças sociais. Observe que, para comunidades vulneráveis, a aquisição de uma parcela de solo urbano não é apenas a moradia, uma vez que, a partir dele, pode-se tornar possível a extração de renda (SANTOS, 2005). Para que existam cidades justas e saudáveis, é preciso que as políticas públicas objetivem a eliminação das desigualdades sociais, da segregação dos indivíduos em razão do tipo e localização da moradia que habitam.

A vulnerabilidade socioambiental remonta desde o início da colonização no Brasil, o solo urbano e a propriedade imobiliária pertencem à classe dominante. Tal problemática nunca foi resolvida no âmbito político-social, ocasionando, ao longo do tempo, déficit urbano e aprofundamento dos problemas sociais e urbanos.

O meio ambiente urbano é um meio ambiente construído e, mesmo não sendo do tipo natural, é patrimônio ambiental de uso comum do povo, estando na proteção conferida pelo artigo 225 , da Constituição (BRASIL, 1988), que estabelece que é direito de todos um meio ambiente ecologicamente equilibrado, bem de uso do povo e essencial a uma qualidade de vida sadia, à qual é uma consequência das condições sociais. Ele é, também, o reflexo da tensão causada pelas desigualdades. Conforme Santos, viver 
na periferia não torna as pessoas pobres, mas a situação de pobreza as conduzem à periferia, já que um dos princípios básicos da estruturação do espaço urbano é o da precificação da centralidade (SANFELICE, 2016).

O desenvolvimento urbano sustentável deve ser um orientador na condução de políticas e práticas durante o processo de expansão e transformação urbana, norteando a formulação de políticas públicas para a construção de um ambiente urbano equilibrado e justo, não devendo as ações de planejamento se restringir apenas aos aspectos naturais. Deve-se analisar, de forma sistemática, a vulnerabilidade das cidades e sua capacidade, ou não, de oferecer serviços e políticas sociais para mitigar a vulnerabilidade de seus habitantes (OJIMA, 2012), uma vez que os problemas ambientais e sociais existentes são a consequência de um modelo econômico de desenvolvimento excludente (UNFPA, 2007).

As Políticas Públicas, entendidas como o “Estado em ação" (GOBERT et al., 1987, citado por HÖFLING, 2001), devem ser observadas em sua integralidade, sob os prismas social, político e jurídico, uma vez que sua base é o Direito, mas o conteúdo material são os fins e objetivos do Estado e da sociedade (RECK et al., 2016).

O adensamento populacional, a expansão para áreas periféricas e os altos níveis de pobreza conjugados marcam profundamente a configuração das cidades brasileiras e contribuem para o agravamento dos principais problemas ambientais urbanos e da qualidade de vida da população, devendo o poder público desempenhar um papel preponderante na gestão das cidades, formulando ações e programas habitacionais e de desenvolvimento urbano.

Calgaro et al. (2017) destacam que a realização de políticas públicas no espaço local é relevante para que a população interessada, conhecedora de sua problemática, possa participar da tomada de decisões em seu Município, exercendo à cidadania social.

Por fim, afirma Serapione (2016) que é mister a avaliação das políticas públicas, observando o alcance e impacto dos objetivos definidos, verificando a efetividade do investimento, bem como a eficiência na distribuição dos recursos. Ainda segundo o autor mencionado, essa etapa acaba por constituir uma importante fase do ciclo político, sendo analisados os efeitos desejados e indesejados, além de monitoramento do desenvolvimento e adaptação da ação pública.

\section{METODOLOGIA}

\section{Caracterização e localização da área de estudo}

A comunidade ribeirinha da llha de Deus está em um território insular, formado a partir da ocupação em área de manguezal (aterros), conforme a dinâmica de crescimento da cidade do Recife, que acabou por empurrar as populações menos favorecidas para áreas periféricas e com risco ambiental. Ela está situada na zona sul da cidade do Recife, no bairro da Imbiribeira, entre os rios Pina, Tejipió e Jordão, localizada no Parque Natural Municipal dos Manguezais Josué de Castro.

Em 1995 ela foi classificada como Zona Especial de Interesse Social- ZEIS Ilha de Deus, diante da verificação dos seguintes requisitos: 1) uso predominantemente habitacional; 2) população com renda familiar igual ou inferior a três salários-mínimos; 3) carência ou ausência de serviços de infraestrutura básica; 
e 4) possibilidade de urbanização, de acordo com relatório do Secretaria de Planejamento e Gestão - Seplag (PERNAMBUCO, 2017).

Vale ressaltar que as ZEIS foram criadas na cidade do Recife em 1983, trazendo uma profunda modificação na abordagem dos núcleos irregulares. Anteriormente, os projetos de urbanização apenas contemplavam melhorias quanto à água, esgoto e luz. Em contraponto, atualmente, a política urbana não mais visa retirar as famílias moradoras de áreas irregulares, mas sim integrá-las à cidade a partir de projetos de infraestrutura urbana e equipamentos públicos, oferecendo serviços aos habitantes, diminuindo o abismo entre a região periférica e a centralidade (PRAZERES, 2018).

Conforme dados levantados em 2003, havia 436 famílias, totalizando, praticamente, 2.000 habitantes (ALMEIDA, 2014), sendo a maioria dedicada a coleta de mariscos há várias gerações, em especial, à extração de sururu e marisco, bem como do cultivo de camarão em viveiros nas margens dos rios.

Para os moradores da llha de Deus, o mangue não é mera fonte de renda, mas um ecossistema ao qual se sentem inseridos por laços naturais e de identidade cultural, havendo um compromisso com o mesmo, através da criação de um senso de sobrevivência devido à elevada dependência para subsistência e geração de renda.

A localidade é um exemplo da conquista de direito à moradia pela comunidade, com reconhecimento pelo Estado de garantia a permanência das famílias no assentamento, mesmo com o entorno protegido por leis ambientais, tendo suas primeiras ocupações datadas da década de 1950, firmando-se, nesta região, pessoas que vinham das cidades do interior de Pernambuco: Sertão, Agreste e municípios de Catende, Ribeirão e Palmares, buscando condições de vida melhores (ALMEIDA, 2014), enfrentando a problemática sócio-econômico-ambiental comuns a outros assentamentos precários, como a falta de saneamento e péssima qualidade das moradias (OLIVEIRA et al., 2009).

\section{Método utilizado}

Partindo do pressuposto do método de abordagem hipotético-dedutivo (PRODANOV et al., 2013), a metodologia utilizada foi a observacional e comparativa, a partir do estudo descritivo e exploratório, utilizando pesquisa bibliográfica, fontes documentais e contatos diretos. Além disso, foi aplicada entrevista estruturada e padronizada por meio de questionário, que foi adaptado do utilizado em tese de doutorado que trata do desenvolvimento socioeconômico e ecológico das comunidades quilombolas (MEDEIROS, 2016).

O questionário foi realizado com os habitantes da Ilha no período de novembro de 2018 a fevereiro de 2019, por amostragem, onde se buscou levantar dados sobre a composição familiar, renda, características da habitação, infraestrutura e serviços públicos básicos oferecidos, programas sociais e perfil dos pescadores.

Após a fase de entrevistas, os dados coletados foram comparados com os índices do IPEA, disponibilizados através do Atlas da Vulnerabilidade Social - IVS, os quais se amparam nos resultados dos censos demográficos do IBGE (MARGUTI et al., 2018), com as informações contidas no Relatório Final do Seplag, disponibilizado em agosto de 2017, bem como com o estudo de Prazeres (2018), sobre os graus de vulnerabilidade socioambiental. 
Cumpre esclarecer que a análise detalhada das informações por setores censitários é de suma importância, mas a comparação dessas informações no tempo é problemática diante dos estudos decenais do IBGE, assim, buscou-se na metodologia trazida por Prazeres (2018) uma alternativa para que que fosse possível avaliar as condições atuais da comunidade.

Por fim, a pesquisa de estudo de caso se deu na modalidade qualitativa diante da natureza que se busca: descrições pessoais e factuais sobre pessoas, lugares e processos interativos, que possibilitam o contato direto do pesquisador com a situação estudada, com a finalidade de observar se houve melhora da qualidade de vida dos moradores da localidade.

\section{Definição de grau de vulnerabilidade socioambiental}

É importante estudar a vulnerabilidade enquanto fenômeno mensurável, possibilitando o julgamento de situações como maior ou menor grau de fragilidade, a fim de estabelecer uma hierarquia de intervenção, destacando as prioridades para as políticas públicas e alocação de recursos (MARTINS et al., 2016).

Os indicadores são importantes porque quantificam um conceito abstrato, subsidiando atividades de planejamento e formulação de medidas a serem adotadas, sendo eficazes para o monitoramento das condições de vida de uma população, de maneira ágil e a um custo baixo (MALTA et al., 2017).

Observa-se que o IDH aborda, sinteticamente, três aspectos básicos do desenvolvimento humano: renda, educação e saúde, não abrangendo todas as dimensões, especialmente quanto à vulnerabilidade, à qual é questão complexa e com especificidades próprias da população afetada. Dessa maneira, a partir de 2010, vêm sendo elaborados outros índices para subsidiar o planejamento de políticas públicas. No Brasil, foi criado o Índice de Vulnerabilidade Social - IVS, do Instituto de Pesquisas Econômicas Aplicadas - IPEA, disponível por uma plataforma digital e que aborda indicadores relacionados à vulnerabilidade e exclusões sociais, também sendo uma importante ferramenta para verificar as desigualdades a que estão submetidas parte significativa da população brasileira (MALTA et al., 2017).

O IVS trata da vulnerabilidade social em três aspectos: (i) infraestrutura urbana, (ii) capital humano e (iii) renda e trabalho. A nova versão da plataforma disponibilizada em 2017, manteve os indicadores produzidos para os anos de 2000 e 2010, mas também acrescentou a séria histórica do PNAD - Pesquisa Nacional de Amostra por Domicílios, de 2011 a 2015.

Em comparação com os dados expostos pelo IBGE, o IVS traz informações mais atualizadas, entretanto ao realizar a pesquisa considerando como área de recorte as Unidades de Desenvolvimento Humano (UDH), especificamente a ZEIS Ilha de Deus, os dados fornecidos remontam apenas aos anos de 2000 e 2010, prejudicando um estudo comparativo uma vez que o plano de ações governamentais na localidade iniciou em 2009 (PERNAMBUCO, 2017).

Assim, para que fosse possível uma avaliação do grau de vulnerabilidade da llha de Deus, foi utilizada a metodologia desenvolvida por Prazeres (2018), com adaptações à realidade local, a qual decorre da mensuração de indicadores sociais, ambientais e infra estruturais adaptados à realidade do local. 
Para a determinação do grau de vulnerabilidade, foram somados os valores atribuídos a cada indicador e definidos conforme intervalo de significância: baixa vulnerabilidade foi definida quando a pontuação mínima está entre os intervalos de 30 a 49 pontos; média vulnerabilidade foi determinada a partir do intervalo entre 50 a 69 pontos; alta vulnerabilidade foi estimada a partir do intervalo de 70 a 90 pontos.

\section{RESULTADOS}

Moradores de área ambientalmente frágil e afetados por implicações da flexibilização da economia do Estado de Pernambuco (ANDRADE, 2008), a Comunidade da Iha de Deus, em 1995, passou a compor o Plano Global de Infraestrutura da Cidade do Recife e se transformou em uma ZEIS - Zonas Especiais de Interesse Social, possuindo, assim, condições e possibilidades de urbanização e regularização fundiária (MORAES et al., 2017).

Após reivindicações da população organizada perante o poder público, em maio de 2007, com o intuito de implantar um projeto modelo de desenvolvimento urbano pela participação ativa da comunidade, o Governo de Pernambuco criou o Plano de Ação Integrada de Investimentos para a ZEIS, após um estudo integrado de dados socioeconômicos, urbanísticos ambientais e sócio organizativos, dimensionando o conjunto de problemas e potencialidades para intervenção, considerando a sua localização em área de manguezal em perímetro urbano (MORAES et al., 2017), bem como a articulação social de seus moradores.

Foram identificados 348 imóveis, sendo que $69 \%$ era atingido pela maré, 22\% palafitas e mais da metade construído com madeira ou resto de materiais (PERNAMBUCO, 2017). Estava flagrante a situação de vulnerabilidade socioambiental verificada a partir da precariedade de condições de vida e proteção social a que estavam submetidos seus moradores, além das mudanças ambientais resultantes da degradação do meio ambiente.

De 2009 a 2015, a região obteve uma nova trajetória em seu desenvolvimento local. Muitas das alterações, ocorridas a partir de estratégias de planejamento e gestões participativas, constituíram uma nova perspectiva na qual conciliasse o crescimento e o desenvolvimento econômico da comunidade (MORAES et al., 2017). Silva et al. (2014) afirmam que a intervenção estatal através das implementações das políticas públicas em oferta de serviços urbanos, saúde e educação concedeu à llha de Deus um novo aspecto de sustentabilidade.

É importante ressaltar que foram disponibilizados três processos de urbanização aos moradores, sendo escolhido um para execução, a fim de que os indivíduos participassem da construção da melhoria conjuntamente, conforme Relatório do Seplag (PERNAMBUCO, 2017), que contemplava: a) Construção de 272 novas casas na Ilha de Deus e de um Conjunto Habitacional próximo à Ilha, com 78 unidades, totalizando 350 novas unidades habitacionais; b) Recomposição de 9.929,71 $\mathrm{m}^{2}$ de manguezal (20.000 mudas de mangue); c) Construção da passarela de acesso à llha de Deus em concreto em substituição ao acesso de madeira; d) Construção, reforma e recuperação de equipamentos comunitários (Unidade de Beneficiamento de pescado, Escola de Remo; Espaço das Marisqueiras, Creche Municipal Saber Viver, Rádio Comunitária Caranguejo Uçá, Unidade de Saúde da Família, Igreja Aprisco de Jesus, Colégio Municipal Capela Santo 
Antônio e Centro Educacional Saber Viver - Padaria Comunitária/Biblioteca/Reforço Escolar/ Salão de Dança).

O Governo do Estado buscou informar e orientar as ações do projeto às famílias, facilitar a educação sanitária e ambiental, bem como o acesso ao trabalho e a melhoria da renda familiar, além da gestão comunitária, compreendendo que a melhoria da qualidade de vida não está adstrita à ocupação de uma nova unidade habitacional ou à implantação de infraestrutura, mas à garantia de acesso a equipamentos e serviços públicos de qualidade, para atingir a máxima ter direito a ter direitos (PERNAMBUCO, 2017).

Nesse novo contexto, a ZEIS Ilha de Deus foi caracterizada sob aspectos socioeconômicos, ambientais e de infraestrutura para melhor indicação sobre sua vulnerabilidade socioambiental. Na observação dos aspectos socioeconômicos foram analisados itens como: assentamento, tempo de formação, unidades habitacionais, número de famílias, situação fundiária, principais problemas, serviços públicos e participação social, ensino e renda.

Quanto aos aspectos ambientais, foram verificados o macrozoneamento, área aproximada da invasão, densidade habitacional, fisiografia da área, área desmatada, área de risco, área alagável, evento de 2010 (elevação do rio acima de $50 \mathrm{~cm}$ ) e a percepção do risco ambiental. Além disso, foram caracterizados sob aspectos da infraestrutura do local, itens como: tipologia habitacional, instalações sanitárias, pavimentação, iluminação pública, rede de abastecimento de água, saneamento básico de esgoto e característica das moradias e urbanísticas.

\section{Caracterização socioeconômica e ambiental da ZEIS Ilha de Deus pós-intervenção}

\section{Da habitação}

O projeto de urbanização da ZEIS Ilha de Deus contemplou um total de 349 moradias para cada família, somando as 78 unidades do conjunto habitacional próximo à localidade e as 272 novas casas na Ilha de Deus, que foram objeto do nosso estudo.

Segundo Andrade (2008), antes da implementação do projeto, a comunidade era composta por casas de madeira $(49,04 \%)$, alvenarias $(46,79 \%)$ e outros materiais $(2,24 \%)$, além de encontrar $24 \%$ dos imóveis assentados em área alagada (palafitas) e 74\% em áreas de chão aterrado. A maioria dos moradores contemplados com as novas habitações já residiam há mais de 30 anos na Comunidade Ilha de Deus.

Atualmente, consoante Figuras 1 e 2, a maioria das habitações estão construídas em alvenaria com reboco (92\%), sendo encontrada poucas em alvenaria sem reboco (1\%) e madeira (1\%). Além disso, a maioria das edificações ocorreram em solo natural (86\%) e impermeabilizado (5\%). Dentre os entrevistados, 5\% não responderam ou não sabiam sobre a tipologia de habitação da residência e $8 \%$ sobre o recuo da Edificação. Rabelo (2010) afirma que, como a maioria dos moradores eram suscetíveis às variações do fluxo da água do Manguezal de Pina, muitos aterravam para construírem suas casas.

Além disso, a ZEIS Ilha de Deus surgiu em consequência do desenvolvimento urbano, sendo composta por população pobre que se instalavam em áreas alagadiças e sujeitas a deslizamentos, da mesma maneira 
que estabeleciam em áreas com restrições à ocupação, isto é, áreas de fragilidade ambiental (RABELO, 2010).

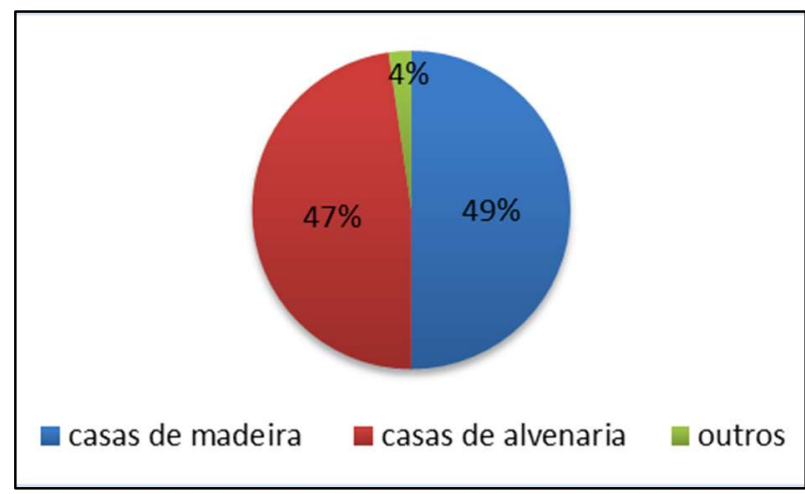

Figura 1: Tipologia da habitação antes do projeto de urbanização.

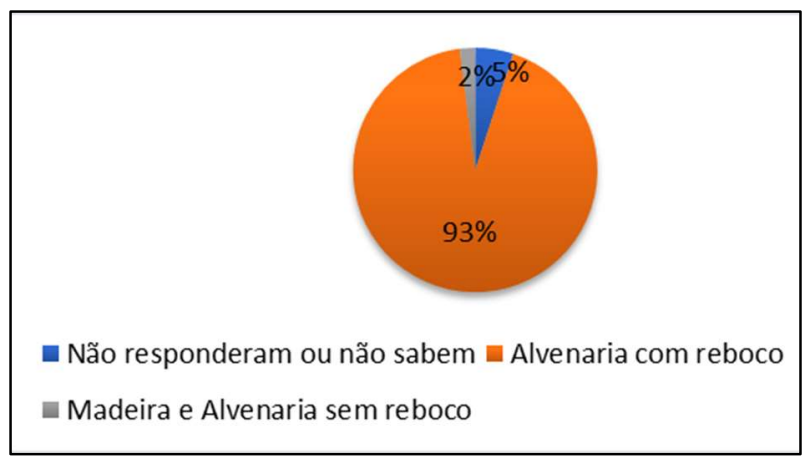

Figura 2: Tipologia da habitação após o projeto de urbanização.

Consoante Relatório do Seplag (PERNAMBUCO, 2017), 69\% dos domicílios eram atingidos pela maré antes do projeto de urbanização. Neste contexto, Malta (2018) afirma que o crescimento urbano fundamentado na área econômica causa desproporções sócios-espaciais, ineficiência e degradação do ambiente.

A maioria das moradias são próprias (79\%), 12\% estão alugadas e 1\% foram cedidas ou invadidas. Conforme exposto na Figura 3, a natureza predominante da ocupação do imóvel é própria sem registro. Tal situação ocorre diante do atraso de entrega das unidades faltantes que acabaram por ser invadidas pelos moradores que estavam à espera de sua conclusão, vivendo em outra localidade, custeados pelos aluguéis sociais pagos pelo Governo do Estado (PERNAMBUCO, 2017).

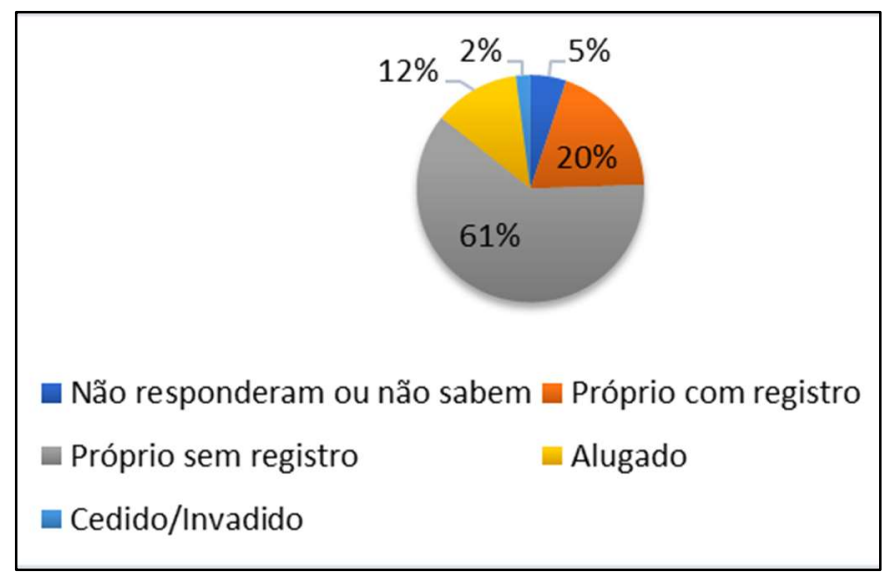

Figura 3: Ocupação do imóvel.

A infraestrutura das residências é básica, digna e resolveu os problemas iniciais de moradia, onde $64 \%$ dos lotes são delimitados, com pisos em cerâmica (63\%) e cimentados (32\%). As coberturas das casas são em telhas de barro (66\%), fibrocimento (2\%) ou laje (2\%). Observou-se que $55 \%$ das moradias são compostas por 2 dormitórios, $8 \%$ possuem 3 e 1\% possui entre 1 e 4 quartos. $34 \%$ dos entrevistados se abstiveram de responder essa questão.

Além disso, todas as casas, após a implementação do projeto do governo, possuem estruturas mais dignas com a obtenção de banheiros internos, pias, chuveiros e vasos com descargas.

Analisando sobre a estrutura das residências, antigamente predominavam os domicílios de 2 até 4 
cômodos (ANDRADE, 2008). Hoje, essas estruturas perfazem com menores índices, onde predominam domicílios com 5 a 7 cômodos, em um total 89\% dos imóveis.

Andrade (2008) e Rabelo (2010) afirmam que todas moradias eram afetadas pelo fluxo de maré do manguezal. Todavia, com a intervenção estatal, $45 \%$ das residências atuais são encontradas em ambiente de vegetação rasteira (capim), 44\% próximas à vegetação arbórea, 5\% próximas à vegetação arbustiva e 5\% não sabem ou não responderam, observando-se uma melhoria quanto à qualidade de vida.

\section{Dos moradores}

Das residências entrevistadas, 5\% são compostas por 2 famílias e 95\% possuem apenas uma família residindo. Dos chefes de família que residem dentre as 73 casas entrevistadas, no universo de $88 \%$ das mulheres/esposas: $25 \%$ são chefes de família; $12 \%$ são famílias sem mãe, sendo os homens chefes de família.

Conforme Figura 4, o grau de instrução que mais se destacou dentre os pais de famílias é o Ensino Fundamental, com $40 \%$ para as mães e $40 \%$ para os pais, seguido pelo analfabetismo com $23 \%$ e $15 \%$ respectivamente.

Quanto à classe de renda familiar por parte dos chefes de família, neste trabalho, $58 \%$ dos entrevistados preferiram não informar a renda média mensal da família. No entanto, dos que responderam, observou-se que a comunidade possui renda média familiar de 1,83 salário-mínimo - SM.

Dos resultados encontrados a maioria das rendas familiares variam entre meio salário-mínimo a um (Figura 5), corroborando com o encontrado por Barbosa (2012, citado por SILVA et al., 2014) em estudo com 33 famílias da comunidade Ilha de Deus, que apontou que 15,15\% das famílias da comunidade recebiam até meio SM. Porém, a maioria das famílias recebiam, em média, entre meio e um salário-mínimo - SM (39,4\%), seguidos dos que recebiam de 1,1 e 2 SM (36,5\%) e salários superior a 2 SM (9\%).

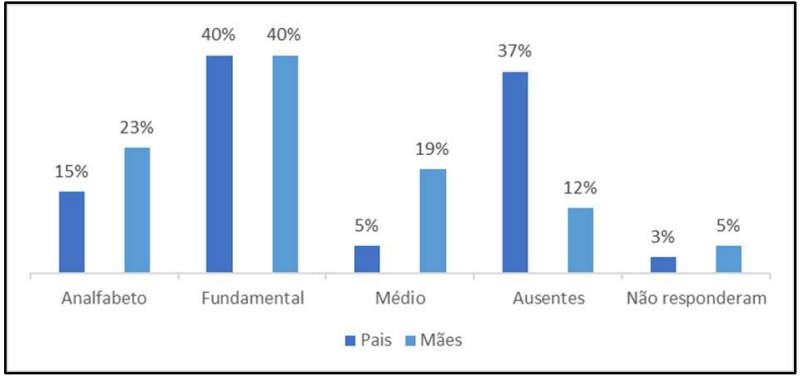

Figura 4: Grau de instrução pais e mães.

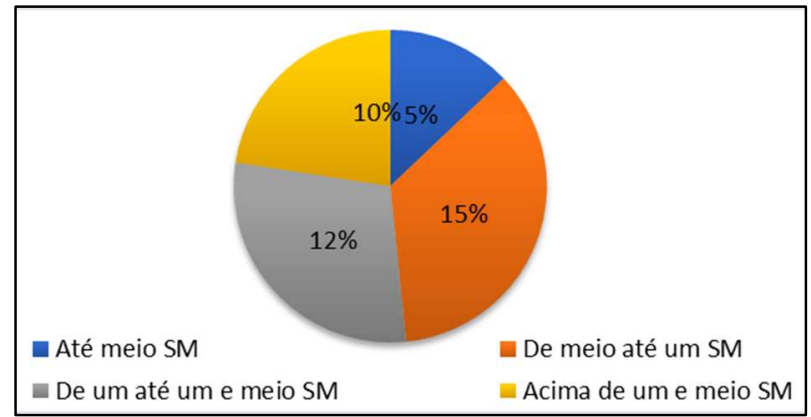

Figura 5: Percentual da renda mensal familiar dos moradores da ZEIS Ilha de Deus

Dentro deste contexto, Rabelo (2010), ao realizar análise do diagnóstico produzido pela FADE/ UFPE sobre a ZEIS Ilha de Deus, inferiu que as rendas familiares média eram menores que um salário-mínimo, onde $11 \%$ recebiam até meio SM; $34,95 \%$ entre meio e um SM; $28,53 \%$ variaram entre um e um e meio SM; $10,89 \%$ entre um e meio a dois SM.

Caracterizados como famílias de baixa renda, conforme descrito no Decreto no 6.135, de 26 de junho de 2007 , os maiores grupos produtivos e de geração de renda da ZEIS são compostos por pescadores (27\%), 
catadores/marisqueiros (26\%) e diaristas, merendeiras e outras especialidades (8\%). Apenas $4 \%$ dessa população corresponde a artesãos. Neste estudo, observou-se uma grande disparidade de abstenção (34\%) por não saberem informar ou optarem por não responder.

\section{Das participações comunitárias e programas sociais}

Dentre o engajamento comunitário, observou-se que boa parte da população participa de grupos não-governamentais (34\%), seguidos de participação na associação dos moradores e outro tipo de organizações (16\%).

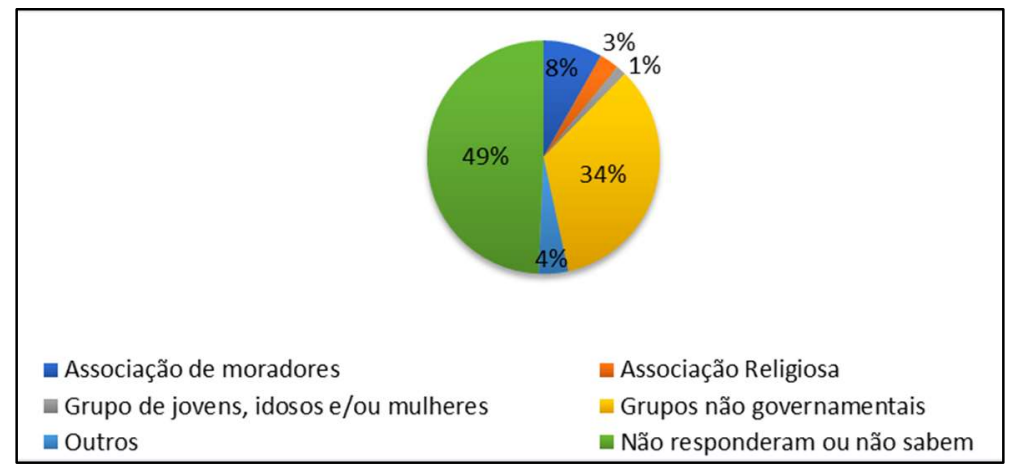

Figura 6: Percentual de participação da comunidade em projetos comunitários

Ademais, $47 \%$ dessas famílias possuem alguém contemplado pelo programa do governo Federal Bolsa Família, 18\% responderam que são contemplados por outros programas e $36 \%$ optaram por não responder ou não possuem ninguém contemplado.

\section{Da infraestrutura}

A Política Nacional de Assistência Social inferiu que o conceito de vulnerabilidade não é apenas vinculado à precariedade ou à inexistência de renda, mas pode ocorrer diante da falta de vínculos familiares e existência de desigualdade quanto ao acesso a bens e serviços públicos (BRASIL, 2005).

Prazeres (2018) considera a fragilidade institucional e a falta de isonomia socioeconômica como riscos, por impedirem o desenvolvimento socioeconômico e impossibilitarem a união social. $\mathrm{O}$ autor supracitado acredita que tais aspectos enfraquecem a solução eficiente de algumas partes da sociedade em casos de eventos ambientais graves.

Baseado nisso, buscou-se obter informações sobre quais riscos sociais, infraestruturais e ambientais a comunidade estar suscetível: $38 \%$ dos entrevistados afirmam que os principais riscos, atualmente, são os derivados de doenças transmissíveis através da água ou decorrente dela e violência urbana. Além disso, 17\% afirmam que a rede elétrica é outro ponto de incidência de risco, além dos alagamentos (15\%). Dos 73 moradores entrevistados, $3 \%$ não souberam responder ou acham que nos locais ainda não há muito periculosidade.

Quando expostos aos fatores de riscos ambientais, $52 \%$ dos moradores buscam abrigos em casas de parentes, $34 \%$ arriscam suas vidas e ficam no local, $7 \%$ buscam abrigos comunitários ou outros lugares e 
outros 7\% não responderam.

Prazeres (2018), avaliando o grau de vulnerabilidade socioambiental dos aglomerados subnormais no município de Itajaí-SC, afirma que a rede de energia elétrica é em desacordo com as normas nessas localidades, uma vez que a população recorre a ligações clandestinas e ilegais para obtenção de energia elétrica, tornando-se suscetíveis a incidentes danosos. Na llha de Deus, observou-se que $23 \%$ dos entrevistados utilizam ligação ilegal diretamente do poste para obter energia; 4\%, relógio comunitário; 70\% possuem relógios próprios; nenhum faz cessão de energia pelo vizinho e $3 \%$ não sabem ou não quiseram responder (Figura 7).

Rolnik et al. (2011), em seu estudo intitulado Crescimento Econômico e Desenvolvimento Urbano, alegam que a vulnerabilidade é decorrente do padrão precário de mobilidade da sociedade que vive em moradias inadequadas, além da ausência da infraestrutura pública. Com isso, verificou-se que, dentre os serviços públicos proporcionados pelo Governo do Estado, 95\% da comunidade têm o abastecimento de água derivado de rede pública, sendo $44 \%$ com medição e $51 \%$ sem medição.

A frequência do abastecimento de água é, em sua maioria, de forma contínua (49\%), sendo seu armazenamento de forma coletiva com caixa superior (4\%) e caixa inferior (1\%) e de maneira individual em caixa d'agua superior (82\%) e também inferior (3\%). Porém, por mais que a maioria das moradias recebam canalização de água direto em suas residências (84\%), 11\% possuem água apenas dentro do terreno.

A qualidade da água para o consumo humano, conforme a percepção dos moradores é: boa (68\%) ou regular (26\%), sendo que $47 \%$ dos moradores afirmaram que não realizam nenhum tratamento para beber diretamente.

Já o escoamento do esgoto ocorre, em sua maioria, a céu aberto, uma vez que $38 \%$ é direcionado para as valas; $18 \%$ são lançados na drenagem, $10 \%$ diretamente para as fossas e $16 \%$ dos moradores buscam outras formas de descarte (Figura 8).

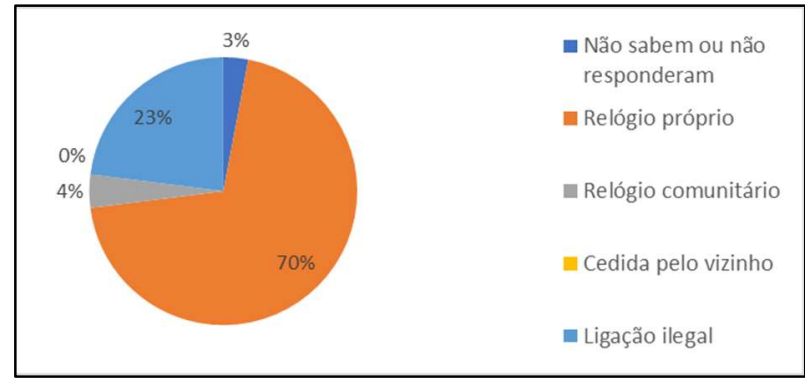

Figura 7: Abastecimento de energia elétrica

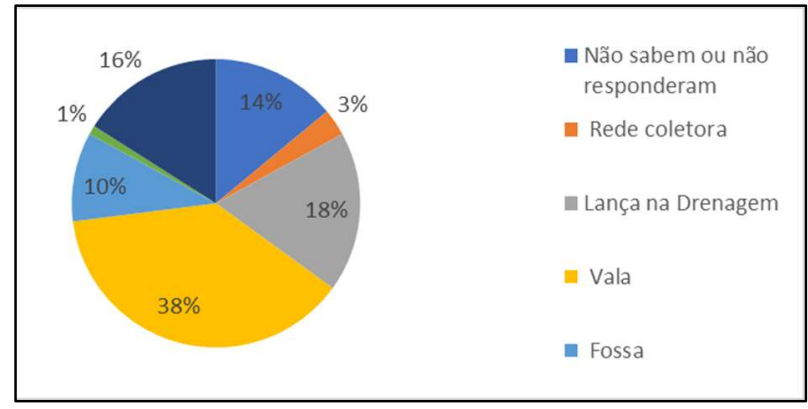

Figura 8: Escoamento do esgoto.

Além disso, o serviço de manutenção do esgoto é feito, principalmente, pela comunidade ou algum morador da mesma (64\%) e, às vezes, pela concessionária responsável pela atividade (23\%). A atuação da prefeitura é irrisória (3\%). Alguns entrevistados que participaram não souberam informar (5\%).

Santos (2005) em seu estudo sobre as políticas públicas e as ações populares: O caso dos Alagados Salvador/BA, encontrou problemas semelhantes com o sistema de drenagem e escoamentos dos resíduos domésticos, após a intervenção do Estado nas comunidades estudadas. O autor constatou que tais 
disfuncionalidades são decorrentes da precariedade das obras.

O serviço de coleta de lixo ocorre diariamente (97\%), sendo coletado de forma domiciliar (96\%). 11\% da comunidade descarta o lixo não coletado a céu aberto; $4 \%$ depositam em terreno baldio e $4 \%$ realizam o aterramento do mesmo.

Comparando os dados acima mencionados com o estudo realizado pelo Instituto Brasileiro de Geografia e Estatística, na pesquisa nacional por amostra de domicílios, dados de 2014 (IBGE, 2015), observase que os moradores da llha de Deus estão na média nacional quanto a acesso a serviços públicos básicos, exceto quando ao esgotamento sanitário, que é um dos seus maiores problemas (Figura 9).

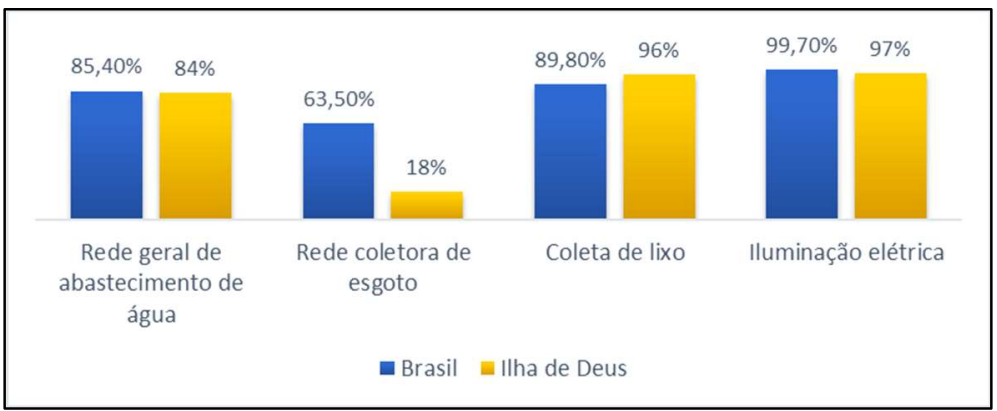

Figura 9: Quadro comparativo média nacional, IBGE, ano 2014 x llha de Deus, ano 2019. Fonte: Adaptado IBGE (2015).

Mesmo com a existência de rede de drenagem em algumas ruas (49\%), ainda há outras que não possuem tal equipamento (42\%). Destarte, dentre a forma de drenagem, a rede separadora - coletores separados para o esgoto sanitário e galerias de águas pluviais - é a que possui um maior percentual: 45\%. No entanto, ainda se observa a drenagem direta para a área de manguezal (19\%).

A comunidade ZEIS Ilha de Deus, além das vulnerabilidades supra apresentadas, possui acessibilidade demorada para educação, segurança pública, lazer e fatores sociais. A acessibilidade a esses serviços, conforme a percepção dos moradores, está caracterizada como bom e/ou regular.

Para alcançar o hospital, os moradores levam um intervalo de até 30 minutos para atingir o local. Os estudantes, seja fundamental ou médio, gastam de 10 até 20 minutos para se deslocarem até a instituição de ensino. Já para deixar seus filhos nas creches, as mães levam uma média de tempo entre 10 a 15 minutos.

\section{Da percepção da comunidade}

Com o intuito de observar qual a percepção da sociedade da ZEIS quanto às obras implementadas pelo governo, 32\% acreditam que a intervenção foi boa uma vez que beneficiou muitas famílias que não possuíam casas próprias e viviam em ambiente de risco; $30 \%$ responderam que foi regular; $12 \%$ defendem como muito boa; $11 \%$ acreditam que foi ruim e 10\% percebem como péssimas (Figura 10).

Levando em consideração as duas últimas percepções, observa-se que ambas ocorreram, principalmente, porque um número expressivo de moradores da comunidade não está mais confiante nas políticas públicas propostas, tendo em vista a existência de casas não finalizadas e, consequentemente, não entregues oficialmente pelo governo. Tais residências acabaram por serem invadidas por seus moradores e concluídas através do sistema de autoconstrução. 


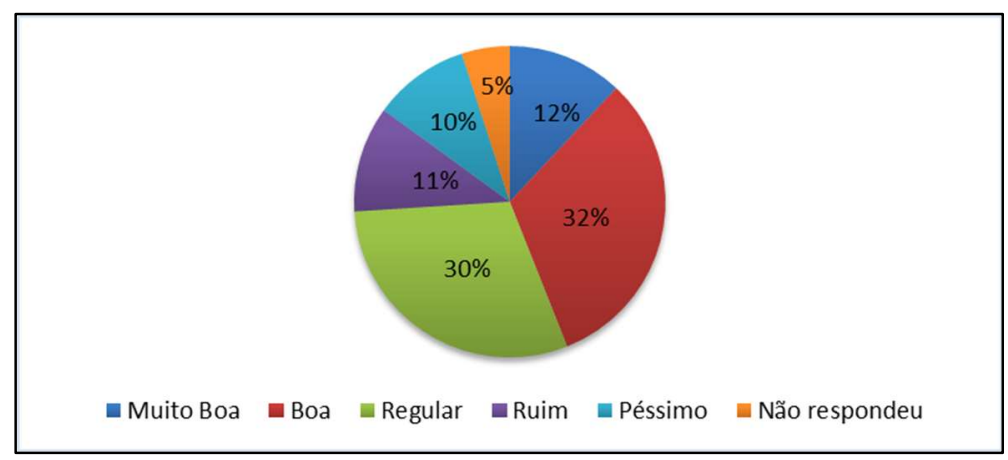

Figura 10: Percentual de satisfação com o projeto de urbanização.

Além disso, há insatisfação de parte da comunidade decorrente da não entrega da creche na localidade, bem como pelas crianças e jovens não possuírem auxílio com transporte para as escolas. Prazeres (2018) acredita que a qualidade das cidades brasileiras e a melhora na vida de seus habitantes podem ser afetadas pelo crescimento desordenado e sem controle.

\section{DISCUSSÃO}

A vulnerabilidade socioambiental relaciona-se diretamente à urbanização, sendo este um dado relevante, uma vez que, no Brasil, mais de $80 \%$ da população brasileira vive em áreas urbanas (MALTA et al., 2017). Assim, buscou-se, no projeto de urbanização realizado na llha de Deus, integrar as dimensões sociais, econômicas e políticas, objetivando o acesso a serviços de saúde, educação, trabalho e lazer.

Tabela 1: Avaliação de vulnerabilidade social.

\begin{tabular}{|c|c|c|c|c|c|}
\hline \multicolumn{6}{|c|}{ Avaliação de Vulnerabilidade Social } \\
\hline \multirow{2}{*}{ Indicadores } & Baixa & Média & Alta & \multirow{2}{*}{ Ilha de Deus } & \multirow{2}{*}{ Pontuação } \\
\hline & 1 & 2 & 3 & & \\
\hline $\begin{array}{l}\text { Número de Famílias } \\
\text { em Coabitação }\end{array}$ & $\begin{array}{lll}\text { Até } 10 \% & \text { de } \\
\text { Coabitações } & \\
\end{array}$ & $\begin{array}{l}\text { De } 11 \% \text { a } 20 \% \text { de } \\
\text { coabitações }\end{array}$ & Acima de $21 \%$ & $5 \%$ & 30 \\
\hline Situação Fundiária & $\begin{array}{l}\text { Documento de } \\
\text { regularização } \\
\text { fundiária até } 10 \%\end{array}$ & $\begin{array}{l}\text { Contrato compra e } \\
\text { venda/Regularização } \\
\text { Fundiária de } 11 \% \text { a } \\
20 \% \\
\end{array}$ & $\begin{array}{l}\text { Sem } \\
\text { documentação/Não } \\
\text { Regularizada Acima } \\
\text { de } 21 \% \\
\end{array}$ & $60 \%$ & 90 \\
\hline $\begin{array}{lr}\text { Participação } & \text { Social, } \\
\text { Institucional } \\
\text { Religiosa }\end{array}$ & $\begin{array}{l}\text { Participação acima } \\
\text { de } 21 \%\end{array}$ & $\begin{array}{l}\text { Participação entre } \\
11 \% \text { até } 20 \%\end{array}$ & $\begin{array}{l}\text { Participação de até } \\
10 \%\end{array}$ & $>21 \%$ & 30 \\
\hline $\begin{array}{l}\text { Renda } \quad \text { Média } \\
\text { Familiar }\end{array}$ & Acima de $3 \mathrm{SM}$ & Entre 2,0 e $2,99 \mathrm{SM}$ & Menos de 1,99 SM & $<1,99 \mathrm{SM}$ & 90 \\
\hline $\begin{array}{l}\text { Grau de Instrução } \\
\text { da Comunidade }\end{array}$ & $\begin{array}{l}\text { Fundamental } \\
\text { incompleto menor } \\
\text { que } 19 \%\end{array}$ & \begin{tabular}{|l} 
Fundamental \\
incompleto \\
$20 \%$ e $29 \%$
\end{tabular} & $\begin{array}{l}\text { Fundamental } \\
\text { incompleto maior } \\
\text { que } 30 \%\end{array}$ & $>30 \%$ & 90 \\
\hline $\begin{array}{l}\text { Profissão/Ocupação } \\
\text { do Chefe de Família }\end{array}$ & $\begin{array}{l}\text { Sem produtividade } \\
\text { até } 19 \%\end{array}$ & $\begin{array}{l}\text { Sem produtividade } \\
\text { entre } 20 \% \text { até } 29 \%\end{array}$ & $\begin{array}{l}\text { Sem produtividade } \\
\text { acima de } 30 \%\end{array}$ & $<19 \%$ & 30 \\
\hline
\end{tabular}

Fonte: Adaptado de Prazeres (2018).

Conforme a conceituação de Duschamps (2004) sobre vulnerabilidade socioambiental, a llha de Deus está na direção de superar tal condição. Considerando os três serviços básicos descritos pela autora como um mínimo de requisitos para não serem considerados em situação de vulnerabilidade, quais sejam, água canalizada em um cômodo; coleta de lixo; e esgotamento sanitário por rede geral/fossa séptica, verificou-se que os moradores, após a intervenção, gozam de bom acesso ao abastecimento de água derivado de rede pública (95\%), embora que 51\% ainda seja sem medição. Outro dado importante: $84 \%$ recebem a água 
canalizada diretamente em suas residências, enquanto que $11 \%$ possuem água apenas dentro do terreno.

Quanto à coleta de lixo, 97\% dos moradores afirmaram que a mesma ocorre diariamente, sendo que 11\% da comunidade ainda descartam o lixo não coletado a céu aberto, o que prejudica as condições sanitárias e ambientais da localidade. Ponto sensível e é no tocante ao esgotamento sanitário. Conforme dados levantados na comunidade, cerca de $38 \%$ do escoamento ainda é direcionado para as valas, conforme Figura 8.

No mesmo sentido, seguindo a metodologia de Prazeres (2018), a partir da análise dos dados coletados pelas entrevistas, relatórios oficiais, levantamento bibliográfico e visitas a comunidade, afere-se que a ZEIS Ilha de Deus apresenta uma média vulnerabilidade socioambiental, conforme as Tabelas 1, 2 e 3.

Tabela 2: Avaliação de vulnerabilidade de infraestrutura.

\begin{tabular}{|c|c|c|c|c|c|}
\hline \multirow{2}{*}{ Indicadores } & Baixa & Média & Alta & \multirow{2}{*}{ Ilha de Deus } & \multirow{2}{*}{ Pontuação } \\
\hline & 1 & 2 & 3 & & \\
\hline Tipologia Habitacional & $\begin{array}{l}\text { Alvenaria com ou } \\
\text { sem reboco }\end{array}$ & $\begin{array}{l}\text { Madeira } \\
\text { aparelhada/Mista }\end{array}$ & $\begin{array}{ll}\text { Madeira } & \text { de } \\
\text { Aproveitamento } & \end{array}$ & Alvenaria & 30 \\
\hline $\begin{array}{l}\text { Instalação Sanitária } \\
\text { Desmembrada da UH }\end{array}$ & Até $10 \%$ das UH & De $10 \%$ até $20 \%$ das UH & Acima de $20 \%$ das UH & $<10 \%$ & 30 \\
\hline $\begin{array}{l}\text { Ausência de Divisórias } \\
\text { Internas na UH }\end{array}$ & Até $10 \%$ das UH & De $10 \%$ até $20 \%$ das UH & Acima de $20 \%$ das UH & $<10 \%$ & 30 \\
\hline $\begin{array}{l}\text { Abastecimento de Água } \\
\text { Alternativo }\end{array}$ & Até $10 \%$ das UH & De $10 \%$ até $20 \%$ das UH & Acima de $20 \%$ das UH & $95 \%$ & 40 \\
\hline Instalação Elétrica Ilegal & Até $10 \%$ das UH & De $10 \%$ até $20 \%$ das UH & Acima de $20 \%$ das UH & $>20 \%$ & 90 \\
\hline $\begin{array}{l}\text { Despejo Irregular de } \\
\text { Esgoto }\end{array}$ & Até $10 \%$ das UH & De $10 \%$ até $20 \%$ das UH & Acima de $20 \%$ das UH & $>20 \%$ & 90 \\
\hline Pavimentação do Entorno & Até $10 \%$ do AS & De $10 \%$ até $20 \%$ do AS & Acima de $20 \%$ do AS & $>20 \%$ & 90 \\
\hline Iluminação Pública & Até $10 \%$ do AS & De $10 \%$ até $20 \%$ do AS & Acima de $20 \%$ do AS & $>20 \%$ & 90 \\
\hline Coleta de Lixo & Até $10 \%$ do AS & De $10 \%$ até $20 \%$ do AS & Acima de $20 \%$ do AS & $<10 \%$ & 30 \\
\hline Rede de Drenagem Pluvial & $\begin{array}{|ll|}\begin{array}{l}\text { Com } \\
\text { pluvial }\end{array} & \text { drenagem } \\
\end{array}$ & $\begin{array}{ll}\text { Parcialmente } & \text { com } \\
\text { drenagem pluvial } & \\
\end{array}$ & \begin{tabular}{|l}
$\begin{array}{l}\text { Sem } \\
\text { pluvial }\end{array}$ \\
\end{tabular} & $\begin{array}{l}\text { Com drenagem } \\
\text { pluvial }\end{array}$ & 90 \\
\hline
\end{tabular}

Fonte: Adaptado de Prazeres (2018).

Tabela 3: Avaliação de vulnerabilidade ambiental.

\begin{tabular}{|c|c|c|c|c|c|}
\hline \multicolumn{6}{|c|}{ Avaliação de Vulnerabilidade Ambiental } \\
\hline \multirow{2}{*}{ Indicadores } & \begin{tabular}{|l|} 
Baixa \\
\end{tabular} & Média & Alta & \multirow{2}{*}{ Ilha de Deus } & \multirow{2}{*}{ Pontuação } \\
\hline & 1 & 2 & 3 & & \\
\hline $\begin{array}{l}\text { Macrozoneamento (conforme } \\
\text { Plano Diretor do Recife) }\end{array}$ & \begin{tabular}{|l|} 
MAC (ZAC, ZRU, \\
ZC) \\
\end{tabular} & MAC (IEP, ZEC, ZEPH) & MANC (ZAN, ZDS, ZEIS) & ZEIS & 80 \\
\hline Fisiografia da Área & Plano & $\begin{array}{l}\text { Plano/Encosta } \\
\text { pequena inclinação }\end{array}$ & $\begin{array}{l}\text { Encostas e/ou Beira de rios } \\
\text { e/ou Área de manguezal }\end{array}$ & \begin{tabular}{|l} 
Área de \\
manguezal
\end{tabular} & 90 \\
\hline Declividade Média & Sem inclinação & Média & Alta & \begin{tabular}{|l|} 
Sem \\
inclinação \\
\end{tabular} & 30 \\
\hline $\begin{array}{lll}\text { Área Desmatada para } \\
\text { Ocupação }\end{array}$ & $\begin{array}{l}\text { Sem } \\
\text { desmatamento }\end{array}$ & $\begin{array}{l}\text { Desmatamento até } \\
30 \% \text { da área }\end{array}$ & $\begin{array}{l}\text { Desmatamento da área } \\
\text { acima de } 30 \%\end{array}$ & $>30 \%$ & 90 \\
\hline $\begin{array}{lll}\text { Área atingida por } \\
\text { enchentes/maré }\end{array}$ & Não & Parcialmente & Sim & Não & 30 \\
\hline
\end{tabular}

Fonte: Adaptado de Prazeres (2018).

Tabela 4: Intervalo de vulnerabilidade ambiental.

\begin{tabular}{|c|c|c|c|}
\hline 30 pontos & 50 pontos & 70 pontos & 90 pontos \\
\hline Baixa Vulnerabilidade & & Média Vulnerabilidade & Alta Vulnerabilidade \\
\hline
\end{tabular}

Somando a pontuação dos indicadores e dividindo pelo número dos mesmos, em uma média aritmética simples, o resultado obtido $(59,52)$ qualifica a llha de Deus como comunidade em situação de média vulnerabilidade socioambiental. 
Observa-se que, embora o IVS do Brasil, a partir de 2011, se manteve na faixa da baixa vulnerabilidade, o IVS do Estado de Pernambuco apresenta uma média vulnerabilidade, com destaque para o IVS da renda e trabalho que apresenta uma alta vulnerabilidade. Já os índices de vulnerabilidade nas dimensões infraestrutura urbana e capital humano estão situados nas faixas de baixa e média vulnerabilidade respectivamente, para o ano de 2017.

Tal análise se coaduna com os dados expostos na Tabela 1, onde se observa que questões como renda e educação ainda são pontos sensíveis de vulnerabilidade na comunidade. Quanto à infraestrutura, foi verificada melhoria da qualidade de vida dos habitantes, mesmo com a persistência da falta de um esgotamento sanitário adequado (Tabela 2). Em relação a esse ponto, o Governo do Estado deveria dar mais prioridade para o término das obras da rede coletora de esgotos, bem como da manutenção do sistema, tendo em vista que são de máxima importância no combate à proliferação de doenças e qualidade de vida das pessoas.

No tocante a seara ambiental, especificamente ao risco de enchentes e/ou exposição a marés, foi observada grande melhoria após as obras de intervenção, considerando que $69 \%$ dos domicílios eram atingidos pela maré, conforme dados levantados no cadastro censitário no período de preparação da ação pública. Atualmente, conforme relato dos moradores, a comunidade não sofre mais problemas de alagamentos ocasionados por fortes chuvas, tampouco pela movimentação da maré.

Esses dados corroboram com Souza et al. (2014), onde infere que as regiões Sul e Sudeste apresentam os mais elevados índices da vulnerabilidade ora mencionada, quando se analisou as áreas de riscos mais vulneráveis aos desastres decorrentes das chuvas em Recife-PE.

Frise-se que a análise acima foi realizada tendo como recorte as 272 novas casas construídas no território da Ilha de Deus. No entanto, verificamos a construção de novas palafitas na face da ilha voltada ao bairro da Imbiribeira, onde moram pessoas em situação de extrema vulnerabilidade e que não estão amparadas por programas de habitação do governo.

Ademais, dos aparelhos que o Governo do Estado firmou compromisso de entrega, ainda restam pendentes: Creche; Espaço das Pescadeiras e Unidade de Beneficiamento do pescado. Observamos que tais itens se fazem importante para melhorar a condição de vulnerabilidade socioambiental, uma vez que contribuem para o desenvolvimento profissional, aumentando a oferta de emprego e elevação de renda da população. Foi verificado, na comunidade, o trabalho de diversas organizações sociais, sendo as principais a Ação Comunitária Caranguejo Uçá e o Centro Educacional Saber Viver.

Constatamos, também, que, diferente de outras comunidades, como o ocorrido nos Alagados (SANTOS, 2005), o poder público optou por deslocar todos os habitantes da comunidade para outra região, durante o período das obras, o que favoreceu a execução do projeto de urbanização. Para tanto, foi disponibilizado aluguel social para que as famílias custeassem uma moradia provisória fora da llha de Deus.

Entretanto, diante da grave crise econômica que assola o Estado de Pernambuco, as obras estão sendo realizadas com lentidão, havendo algumas casas pendentes de entrega, que foram invadidas, conforme o relatório do Seplag (PERNAMBUCO, 2017). O baixo valor do aluguel social, a falta de um meio de 
sustento, além da demora na conclusão das casas, considerando que há moradores que aguardam o reassentamento em lugar provisório há mais de quatro anos (PERNAMBUCO, 2017), são fatores que causam grande tensão entre os moradores e o governo.

Quanto à questão ambiental, embora tenha havido o replantio de área do manguezal, bem como ações e oficinas de educação ambiental para conscientização sobre a preservação do meio ambiente (PERNAMBUCO, 2017), observou-se, empiricamente, que o projeto adotou uma ótica reducionista do ponto de vista arquitetônico-urbanístico, ao desconsiderar a perspectiva do ecossistema da localidade.

Ademais, o descarte do resíduo da coleto de mariscos no manguezal, a continuidade dos viveiros de camarão na região, o lançamento de dejetos pelas novas palafitas e os trazidos pelo movimento da maré são os fatores preocupantes, uma vez que prejudicam a saúde da população e o ecossistema local. Realidade está observada por visitas in loco, informações das entrevistas e conversas informais.

Dessa maneira, mesmo com as profundas alterações ocorridas pelo projeto de urbanização, que melhoraram a qualidade de vida da população a partir de uma verificação empírica, sendo ofertados, principalmente, serviços de infraestrutura urbana, havendo a diminuição do quantitativo de famílias por residência, melhora na qualidade estrutural das moradias e diminuição dos riscos por alagamento, a aplicabilidade de políticas públicas pós-urbanização não foi satisfatória, especialmente em relação à vulnerabilidade social, no tocante a geração de renda.

\section{CONCLUSÕES}

Os problemas ambientais urbanos não são novos nas cidades brasileiras. A situação da moradia é uma consequência das condições sociais, reflexos das tensões causadas pela desigualdade, onde a pobreza faz com que as pessoas residam nas regiões periféricas. Faz-se necessário uma política habitacional eficaz, apenas a urbanização de favelas não tem o condão de alterar a situação de exclusão dos mais vulneráveis. Para tanto, precisa-se de ações integradas, construídas com participação da comunidade, conjugando investimentos públicos e privados, objetivando justiça na distribuição das benesses urbanas.

O projeto de urbanização na Ilha de Deus, com abordagem multidimensional, buscou mitigar a extrema pobreza e promover o desenvolvimento urbano e equilibrado com o meio ambiente. Ele foi ambicioso e inovador, uma vez que não se restringiu à ideia de que a problemática da área se referia apenas à habitação e à infraestrutura urbana, conforme ocorreu em outras comunidades, como os Alagados, Salvador/BA (SANTOS, 2005).

Entretanto, a falta de sua conclusão pelo poder público repercutiu em condições insatisfatórias nas searas sociais, econômicas, urbanísticas e ambientais. Parte das obras, que tinha expectativa de finalização até 2014, está pendente de término. Observa-se, também, a existência de alto índice de risco ambiental e da falta de políticas e ações conjuntas de gestão do espaço urbano, através de medidas coordenadas, os quais favorecem situação de fragilidade.

Pela análise do material coletado, verifica-se melhora da qualidade de vida dos moradores após a ação pública, que conseguiu mitigar a situação de vulnerabilidade socioambiental da comunidade, 
propiciando uma existência mais digna.

Assim, faz-se importante a revisão do projeto, por parte do governo, ressaltando a importância dos meios de avaliação das ações públicas, sendo esta uma etapa importante para mensuração da efetividade do investimento, eficácia na prestação de serviço ao cidadão, transparência e participação da população, bem como análise de pontos de inflexão, a fim de subsidiar o desenvolvimento e adequação continuada dos programas sociais às novas realidades que vão surgindo.

A precariedade vivida na periferia dificilmente será superada sem uma visão holística abrangendo a política habitacional e os problemas ambientais, devendo existir uma integração de programas sociais e econômicos nessas áreas, atendendo as necessidades da comunidade beneficiada em consonância aos interesses da cidade.

\section{REFERÊNCIAS}

ACSELRAD, H.. Vulnerabilidade social, conflitos ambientais e regulação urbana. O Social em Questão, v.28, n.33, 2015.

ALMEIDA, A. C. S.; MEDEIROS, M. D. S.; MAJELLA, G., LOPES, B.; OLIVEIRA, R. J.; RIBEIRO, N. M. A. R.. Caracterização e Avaliação do Consumo de Lenha da Atividade Extrativista de Coleta de Marisco e do Sururu da Comunidade da llha de Deus. ANEF Revista Científica Digital, Recife, n.1, 2014.

ANDRADE, A. C.. Gestão de áreas verdes em ambientes urbanos: (uma contribuição à análise e resolução de conflitos sócio ambientais). Dissertação (Mestrado em Gestão em Políticas Públicas) - Universidade Federal de Pernambuco, Recife, 2008.

IPEA. Instituto de Pesquisa Econômica Aplicada. Atlas da Vulnerabilidade Social. Repositório do Conhecimento IPEA. 2018.

BARBOSA, M. S. M.; LIMA, K. S. C.; FRIEDE, R. R.; MIRANDA, M. G.. A relação entre pobreza e degradação ambiental no Brasil, sob a ótica dos indicadores PIB/IDH. Semioses, Rio de Janeiro, v.9, n.1, p.17-35, 2015.

BRASIL. Constituição da República Federativa do Brasil de 1988. Brasília: DOU, 1988.

BRASIL. Ministério do Desenvolvimento Social e Combate à Fome. Política Nacional de Assistência Social PNAS/2004 e Norma Operacional Básica NOB/SUAS. Brasília: MDS, 2005.

CALGARO, C.; PEREIRA, A. O. K.. Políticas públicas e cooperação social em John Rawls. Veredas do Direito, Belo Horizonte, v.14, n.28, p.277-302, 2017. DOI: https://doi.org/10.18623/rvd.v14i28.970

CORRÊA, R. L.. O espaço urbano. São Paulo: Ática, 1989.

DESCHAMPS, M. V.. Vulnerabilidade socioambiental na região metropolitana de Curitiba. Tese (Doutorado em Meio Ambiente e Desenvolvimento) - Universidade Federal do Paraná, Curitiba, 2004.

HARVEY, D.. O direito à cidade. Lutas Sociais, São Paulo, n.29, p.73-89, 2012.
HÖFLING, E. M.. Estado e políticas (públicas) sociais. Caderno Cedes, Campinas, v.21, n.55, p.30-41, 2001. DOI: https://doi.org/10.1590/S0101-32622001000300003

IBGE. Instituto Brasileiro de Geografia e Estatística. Pesquisa nacional por amostra de domicílios: síntese de Indicadores, 2013-2014. Rio de Janeiro: IBGE, 2015.

JACOBI, P. R.. Cidade e meio ambiente: percepções e práticas em São Paulo. São Paulo: Annablume, 2000.

MAIOR, M. M. S.; CÂNDIDO, G. A.. Avaliação das metodologias brasileiras de vulnerabilidade socioambiental como decorrência da problemática urbana no Brasil. Caderno Metropolitano, São Paulo, v.16, n.31, p.241-264, 2014.

MALTA, F. S.. Vulnerabilidade Socioambiental: Proposta Metodológica e Diagnóstico para o Município do Rio de Janeiro. Tese (Doutorado em Planejamento Energético) Universidade Federal do Rio de Janeiro, Rio de Janeiro, 2018.

MALTA, F. S.; COSTA, E. M. D.; MAGRINI, A.. Índice de vulnerabilidade socioambiental: uma proposta metodológica utilizando o caso do Rio de Janeiro, Brasil. Ciência \& Saúde Coletiva, v.22, n.12, p.3933-3944, 2017.

MARGUTI, B. O.; PINTO, C. V. D. S.; ROCHA, B. N.; COSTA, M. A.; CURI, R. L. C.. A Nova plataforma da vulnerabilidade social: primeiros resultados do índice de vulnerabilidade social para a série histórica da PNAD (2011-2015) e desagregações por sexo, cor e situação de domicílios. Repositório do Conhecimento IPEA, 2018.

MARTINS, M. H. DA M.; TAVANTI, R. M.; SPINK, M. J. P.. Versões de vulnerabilidade em artigos científicos Brasileiros sobre desastres ambientais. Athenea Digital, v.16, n.3, p.347-366, 2016.

DOI: https://doi.org/10.5565/rev/athenea.2007

MEDEIROS, A. C.. Índice de desenvolvimento socioeconômico e ecológico: um estudo contributivo às comunidades quilombolas do Estado da Paraíba. Tese (Doutorado em Recursos Naturais) - Universidade Federal de Campina Grande, Campina Grande, 2016. 
MORAES, F. M.; MARQUES, G. V. G.. Planejamento urbano e participação popular: a experiência do plano de ação integrada de investimentos para a ZEIS Ilha de Deus, Recife Pernambuco. In: ENCONTRO NACIONAL DA REDE DE OBSERVATÓRIO DAS METRÓPOLES. Anais. Natal: UFRN, 2017.

OJIMA, R.. A Vulnerabilidade socioambiental como conceito interdisciplinar: avanços e potencialidades para pensar mudanças ambientais. Revista Cronos, Natal, v.13, n.1, p.110-120, 2012.

OLIVEIRA, M. F.; ANDRADE, T. L. C.. O Homem - Caranguejo do Século XXI: A Organização Social da llha de Deus como Nova Perspectiva de Comunidade Riberinha. In: CONGRESSO DE INICIAÇÃO CIENTÍFICA, 27; CONGRESSO DE INICIAÇÃO EM DESENVOLVIMENTO TECNOLÓGICO E INOVAÇÃO,1. Anais. 2009.

PERNAMBUCO. Secretaria de Planejamento e Gestão. Gerenciamento de Ação Integrada de Investimentos para a Zeis Ilha de Deus: Relatório Final. Recife: Seplag, 2017.

PRAZERES, A.. Avaliação do Grau de Vulnerabilidade Socioambiental dos Aglomerados Subnormais no Município de Itajaí-SC. Dissertação (Mestrado em Ciência e Tecnologia Ambiental) - Universidade do Vale do Itajaí, Itajaí, 2018.

PRODANOV, C. C.; FREITAS, E. C.. Metodologia do trabalho científico: métodos e técnicas da pesquisa e do trabalho acadêmico. 2 ed. Novo Hamburgo: Feevale, 2013.

RABELO, J. B.. Habitação e Sustentabilidade em Áreas de Fragilidade Ambiental. Periódico eletrônico: Fórum Ambiental da Alta Paulista, São Paulo, v.6, n.5, p.323-337, 2010.

RECK, J. R.; BTENCOURT, C. M.. Categorias de análise de políticas públicas e gestão complexa e sistêmica de políticas públicas. A\&C: Revista de Direito Administrativo \& Constitucional, Belo Horizonte, v.16, n.66, p.131-151, 2016. DOI: http://dx.doi.org/10.21056/aec.v16i66.364

ROLNIK, R.; KLINK, J.. Crescimento econômico e desenvolvimento urbano: Por que nossas cidades continuam tão precárias?. Novos Estudos: CEBRAP, São Paulo, n.89, p.89-109, 2011. DOI: https://doi.org/10.1590/S0101$\underline{33002011000100006}$

SANFELICE, D.. A centralidade das aglomerações metropolitanas na economia globalizada: fundamentos econômicos e possibilidades políticas. Caderno

Metropolitano, São Paulo, v.18, n.37, p.623-646, 2016. DOI: https://doi.org/10.1590/2236-9996.2016-3701

SANTOS, J.. Políticas públicas e ações populares: o caso dos alagados Salvador/BA. Estudos Geográficos, Rio Claro, v.1, n.3, p.93-110, 2005

SERAPIONI, M.. Conceitos e métodos para a avaliação de programas sociais e políticas públicas. Revista da Faculdade de Letras da Universidade do Porto, v.31, p.59-80, 2016.

SILVA, B. C. T. D.; CORREA, E. B.; PEDROSA, I. V. Desenvolvimento periférico: uma análise da intervenção do estado ocorrida na Comunidade Ilha de Deus, Pernambuco, Brasil. In: ENCONTRO PERNAMBUCANO DE ECONOMIA: POLÍTICAS PARA O DESENVOLVIMENTO ESTADUAL, 3. Anais. Recife: UFPE, 2014.

SILVA, L. S.; TRAVASSOS, L.. Problemas ambientais urbanos: desafios para a elaboração de políticas públicas integradas. Cadernos Metrópole, São Paulo, n.19, p.27-47, 2008.

SOUZA, W. M.; AZEVEDO, P. V.; ASSIS, J. M. D. O.; SOBRAL, M. D. C. M.. Áreas de risco mais vulneráveis aos desastres decorrentes das chuvas em Recife-PE. Revista Brasileira de Ciências Ambientais, Rio de Janeiro, n.34, p.79-94, 2014.

SPINK, M. J. P.. Viver em áreas de risco: tensões entre gestão de desastres ambientais e os sentidos de risco no cotidiano. Ciência e Saúde Coletiva, v.19, n.9, 2014. DOI: https://doi.org/10.1590/1413-81232014199.01182014

UNFPA. United Nations Populations Fund. State of world population 2007: unleashing the potential of urban growth. New York: UNFPA, 2007.

A CBPC - Companhia Brasileira de Produção Científica (CNPJ: 11.221.422/0001-03) detém os direitos materiais desta publicação. Os direitos referem-se à publicação do trabalho em qualquer parte do mundo, incluindo os direitos às renovações, expansões e disseminações da contribuição, bem como outros direitos subsidiários. Todos os trabalhos publicados eletronicamente poderão posteriormente ser publicados em coletâneas impressas sob coordenação da Sustenere Publishing, da Companhia Brasileira de Produção Científica e seus parceiros autorizados. Os (as) autores (as) preservam os direitos autorais, mas não têm permissão para a publicação da contribuição em outro meio, impresso ou digital, em português ou em tradução. 